\title{
Cytochrome P450 expression in oesophageal cancer
}

\author{
G I Murray, D Shaw, R J Weaver, J A McKay, S W B Ewen, W T Melvin, M D Burke
}

\begin{abstract}
The cytochrome $\mathbf{P 4 5 0}$ superfamily of enzymes play a central part in the metabolism of carcinogens and anti-cancer drugs. The expression, cellular localisation, and distribution of different forms of $\mathbf{P 4 5 0}$ and the functionally associated enzymes epoxide hydrolase and glutathione S-transferases have been investigated in oesophageal cancer and non-neoplastic oesophageal tissue using immunohistochemistry. Expression of the different enzymes was confined to epithelial cells in both non-neoplastic samples and tumour samples except that CYP3A was also identified in mast cells and glutathione $S$ transferase pi was present in chronic inflammatory cells. CYP1A was present in a small percentage of non-neoplastic samples but both CYP2C and CYP3A were absent. Epoxide hydrolase was present in half of the nonneoplastic samples and the different classes of glutathione S-transferase were present in a low number of samples. In carcinomas CYP1A, CYP3A, epoxide hydrolase, and glutathione $S$-transferase pi were expressed in at least $60 \%$ of samples. The expression of glutathione S-transferases alpha and mu were significantly less in adenocarcinoma compared with squamous carcinoma.

(Gut 1994; 35: 599-603)
\end{abstract}

Oesophageal cancer is one of the commonest malignancies of the alimentary tract and this tumour is often intrinsically resistant to anticancer drugs. ${ }^{1}$ The geographical distribution of oesophageal cancer has led to the hypothesis that exposure to various toxic environmental or dietary chemicals is an important aetiological factor. ${ }^{2}$ The principal groups of enzymes responsible for metabolising toxic exogenous chemicals, including anti-cancer drugs and carcinogens, are the cytochromes P450, epoxide hydrolases, and glutathione S-transferases. ${ }^{3-7}$ Therefore these functionally associated groups of enzymes have important roles in determining the susceptibility of tissues to the toxic effects of xenobiotics and the response of tumours to anticancer drugs. ${ }^{4-10}$

The cytochromes $\mathrm{P} 450$ are a multigene superfamily of haem containing enzymes that metabolise both xenobiotics (including carcinogens, mutagens, and therapeutic drugs) and a variety of endogenous compounds (including steroid hormones, arachidonic acid, and fatty acids). ${ }^{41-14}$ The major xenobiotic metabolising families of $\mathbf{P} 450$ are primarily expressed in the liver, although specific forms of P450 are present in particular extrahepatic tissues. The epoxide hydrolases and glutathione S-transferase are two groups of enzymes that participate in the further metabolism of compounds initially metabolised by $\mathrm{P} 450$. Epoxide hydrolases participating in xenobiotic metabolism comprise mainly one microsomal and one cytosolic form, which convert potentially toxic epoxides to less reactive dihydrodiols, although subsequent reoxidation can lead to the formation of diol-epoxide derivatives, which are often more toxic than the parent compounds. ${ }^{5}$ The glutathione S-transferases, like the cytochromes P450, are a complex gene family of enzymes, which catalyse the conjugation of reduced glutathione with a variety of electrophilic compounds generally resulting in less toxic, more hydrophilic compounds, which can be more easily excreted. ${ }^{6}{ }^{15}$ Like the cytochromes P450 the liver is the main organ in which the glutathione S-transferases are expressed and specific classes of glutathione S-transferases are present in many extrahepatic tissues.

There is little information regarding the presence, distribution, and localisation of different xenobiotic metabolising enzymes in either normal oesophagus or oesophageal tumours and in this study we have investigated the expression of different forms of P450, epoxide hydrolase, and glutathione S-transferase in oesophageal carcinoma and non-neoplastic oesophageal tissue.

\section{Materials and methods}

\section{ANTIBODIES}

CYP1A and CYP3A were identified using monoclonal antibodies $\mathrm{RM} 3^{16}$ and $\mathrm{HL} 3^{17}{ }^{18}$ respectively, which have been raised and characterised in our laboratories as described previously. (Individual families and forms of P450 are identified in this study using the designation CYP according to the recent updated nomenclature for cytochrome P450. ${ }^{12}$ The $\mathrm{P} 450$ forms recognised by immunoreactivity in this study are classified according to their sub-family and not identified as being individual members of subfamilies as it is not known whether the antibodies are specific to certain sub-family members). CYP2C was identified with a rabbit polyclonal antibody raised in our laboratories against the purified human hepatic form CYP2C9, P450hB. ${ }^{19}$ Epoxide hydrolase was recognised using a rabbit polyclonal antibody raised and characterised in our laboratories against a purified preparation of human hepatic microsomal epoxide hydrolase. ${ }^{20}$ Three major cytoplasmic classes of glutathione S-transferases (alpha, mu, and pi) were identified individually using rabbit polyclonal antibodies obtained from Novocastra Laboratories, Newcastle upon Tyne. All the antibodies used in this study recognise antigenic epitopes, which are resistant to formalin fixation and wax embedding. 
TISSUE

Specimens of oesophageal cancer and nonneoplastic oesophagus were obtained from oesophagectomy specimens submitted to the Department of Pathology, University of Aberdeen for diagnostic purposes. All the tissue samples had been fixed in $10 \%$ neutral buffered formalin for 24 hours at room temperature and then routinely processed to paraffin wax.

\section{IMMUNOHISTOCHEMISTRY ${ }^{21}$}

Formalin fixed wax embedded sections $(4 \mu \mathrm{m})$ of oesophagus were dewaxed in xylene, rehydrated in alcohol, and then washed sequentially in cold water and $0.05 \mathrm{M}$ TRIS-HCl $(\mathrm{pH} \mathrm{7.6)}$ containing $0.15 \mathrm{M}$ sodium chloride (TBS) and then immunostained with various antibodies as described below. Both negative and positive controls were incorporated in the immunohistochemical procedure. Negative controls used in place of the primary antibody were either TBS (control for monoclonal antibodies), or normal rabbit immunoglobulins (control for polyclonal antibodies). Positive controls were sections of normal formalin fixed wax embedded human liver as liver is known to express all the enzymes being studied.

The sections were examined using transmitted light microscopy to establish qualitatively the presence or absence of immunostaining, and its distribution.

Correlations between the expression of the different enzymes were determined using the $\chi^{2}$ test with Yates's correction.

\section{MONOCLONAL ANTIBODIES}

Sections of tissue were incubated for one hour with each of the monoclonal antibodies at the following dilutions: anti-CYP1A (RM3), 1/20

TABLE I Number (percentage) of oesophageal samples expressing different number of xenobiotic metabolising enzymes

\begin{tabular}{llll}
\hline $\begin{array}{l}\text { Noof } \\
\text { xenobiotic } \\
\text { metabolising } \\
\text { enzymes } \\
\text { expressed }\end{array}$ & $\begin{array}{l}\text { Non-neoplastic } \\
\text { oesophagus } \\
(n=10)\end{array}$ & $\begin{array}{l}\text { Squamous } \\
\text { carcinoma } \\
(n=25)\end{array}$ & $\begin{array}{l}\text { Adenocarcinoma } \\
(n=25)\end{array}$ \\
\hline 0 & $2(20)$ & 0 & 0 \\
1 & $4(40)$ & $2(8)$ & $2(8)$ \\
2 & $1(10)$ & $4(16)$ & $5(20)$ \\
3 & $1(10)$ & 0 & $8(32)$ \\
4 & $1(10)$ & $2(8)$ & $1(4)$ \\
5 & $1(10)$ & $8(32)$ & $5(20)$ \\
6 & 0 & $6(24)$ & $3(12)$ \\
7 & 0 & $3(12)$ & $1(4)$ \\
\hline
\end{tabular}

TABLE II Number (percentage) of non-neoplastic oesophageal samples and distinct histological types of oesophageal cancer expressing different xenobiotic metabolising enzymes

\begin{tabular}{llll}
\hline Xenobiotic metabolising enzyme & $\begin{array}{l}\text { Non-neoplastic } \\
\text { oesophagus } \\
(n=10)\end{array}$ & $\begin{array}{l}\text { Squamous } \\
\text { carcinoma } \\
(n=25)\end{array}$ & $\begin{array}{l}\text { Adenocarcinoma } \\
(n=25)\end{array}$ \\
\hline CYP1A & $3(30)$ & $17(68)$ & $15(60)$ \\
CYP2C & 0 & $8(32)$ & $5(20)$ \\
CYP3A & 0 & $19(76)$ & $17(68)$ \\
Epoxide hydrolase & $5(50)$ & $21(84)$ & $24(96)$ \\
Glutathione S-transferase alpha & $4(40)$ & $19(76)$ & $8(32)$ \\
Glutathione S-transferase mu & $2(20)$ & $15(60)$ & $5(20)$ \\
Glutathione S-transferase pi & $2(20)$ & $16(64)$ & $16(64)$ \\
\hline
\end{tabular}

dilution in TBS of a $50 \%$ ammonium sulphate precipitate of hybridoma culture supernatant, and anti-CYP3A (HL3) as undiluted hybridoma culture supernatant. Sites of antibody binding were shown using an alkaline phosphatase antialkaline phosphatase (APAAP) technique. Rabbit antimouse immunoglobulin (1/100 containing $1 \%$ normal human serum, Dako Ltd, High Wycombe, Bucks) and monoclonal $\operatorname{APAAP}(1 / 100$, Dako) were sequentially applied to the tissue sections for 30 minutes each. Between antibody applications the sections were washed with TBS to remove unbound antibody. Sites of bound alkaline phosphatase were shown using an enzyme substrate solution containing $3 \mathrm{mg}$ bromo-chloro-indolyl phosphate (Sigma Chemical Co Ltd, Poole, Dorset), $10 \mathrm{mg}$ nitro blue tetrazolium (Sigma), $6 \mathrm{mg}$ sodium azide, and $4 \mathrm{mg}$ levamisole (Sigma) in $10 \mathrm{ml} 0.05 \mathrm{M}$ TRIS-HCl buffer ( $\mathrm{pH} 9.0$ ) containing $0.2 \%$ magnesium chloride. After incubating the sections for 30 minutes at room temperature, the reaction was stopped by washing the sections in cold tap water. The slides were then air dried and mounted in glycerine jelly.

\section{POLYCLONAL ANTIBODIES}

Anti-CYP2C was applied to tissue sections at a dilution of 1 in 500 (stock solution $20 \mathrm{mg} / \mathrm{ml}$ in TBS prepared from the lyophilate of a $50 \%$ ammonium sulphate precipitate of immunised rabbit serum). Anti-epoxide hydrolase was applied at a dilution of $1 / 50$ of a stock $20 \mathrm{mg} / \mathrm{ml}$ solution, prepared from the lyophilate of a $50 \%$ ammonium sulphate precipitate of immunised rabbit serum. Antibodies to the different classes of glutathione S-transferase were applied at the following dilutions of a stock solution (protein concentration $1 \mathrm{mg} / \mathrm{ml}$ ): glutathione S-transferase alpha $1 / 100$; glutathione S-transferase mu $1 / 50$; glutathione S-transferase pi $1 / 200$. The antibodies were applied to tissue sections for one hour at room temperature, and the sites of bound antibody shown using the APAAP technique. After removal of unbound primary antibody, the sections were incubated with monoclonal mouse antirabbit immunoglobulin (1/100, Dako) for 30 minutes before application of rabbit antimouse immunoglobulin, APAAP, and alkaline phosphatase substrate solution. The sections were then processed as described above.

\section{Results}

NON-NEOPLASTIC OESOPHAGUS

Tissue samples obtained from proximal resection margins of 10 oesophagectomy specimens that had been excised for squamous carcinoma were used to investigate the presence of the various enzymes in non-neoplastic oesophagus. These specimens contained all layers of the oesophagus including both squamous epithelial lining and muscularis. CYP1A immunoreactivity was identified in $30 \%$ of samples and there was no immunoreactivity for either CYP2C 9 or CYP3A in any of the non-neoplastic specimens of oesophagus. Epoxide hydrolase was identified in $50 \%$ of the samples and immunoreactivity for 
the different classes of glutathione S-transferase alpha, pi, and mu was present in 40, 20, and $20 \%$ of the samples respectively. In all cases the positive immunoreactivity was identified with the stratified squamous epithelium with immunostaining being present in all layers of the epithelium. Connective tissue, blood vessels, and smooth muscle showed no immunostraining.

\section{OESOPHAGEAL CANCER}

Fifty oesophageal cancers were studied consisting of 25 squamous carcinomas and 25 adenocarcinomas. Based on immunoreactivity, all the carcinomas expressed at least one enzyme and four tumours expressed all seven enzymes (Table I). CYP1A, CYP2C, and CYP3A were identified in 32,13 , and 36 tumours respectively $(64,26$, and $72 \%$ of the neoplasms respectively). There was widespread expression of epoxide hydrolase with 45 (90\%) of tumours showing positive immunoreactivity. Glutathione S-transferase alpha, $\mathrm{mu}$, and pi were present in 27, 20, and 32 of carcinomas respectively $(54,40$, and $64 \%$ of tumours respectively). Table II summarises the detailed expression of the various xenobiotic metabolising enzymes in the different histological types of oesophageal cancer. The expression of glutathione S-transferase alpha $\left(\chi^{2}\right.$, $\mathrm{p}=\mathbf{0 . 0 0 5}, \mathbf{1}$ degree of freedom) and glutathione S-transferase mu $\left(\chi^{2}, p=0.009,1\right.$ degree of freedom) were significantly less in adenocarcinomas compared with squamous carcinomas. The expression of all the other enzymes was similar in the different histological types of oesophageal cancer.

Immunoreactivity for each enzyme was present in the cytoplasm of tumour cells (Figs 1-3), although in a few cases nuclear staining for the different classes of glutathione S-transferases

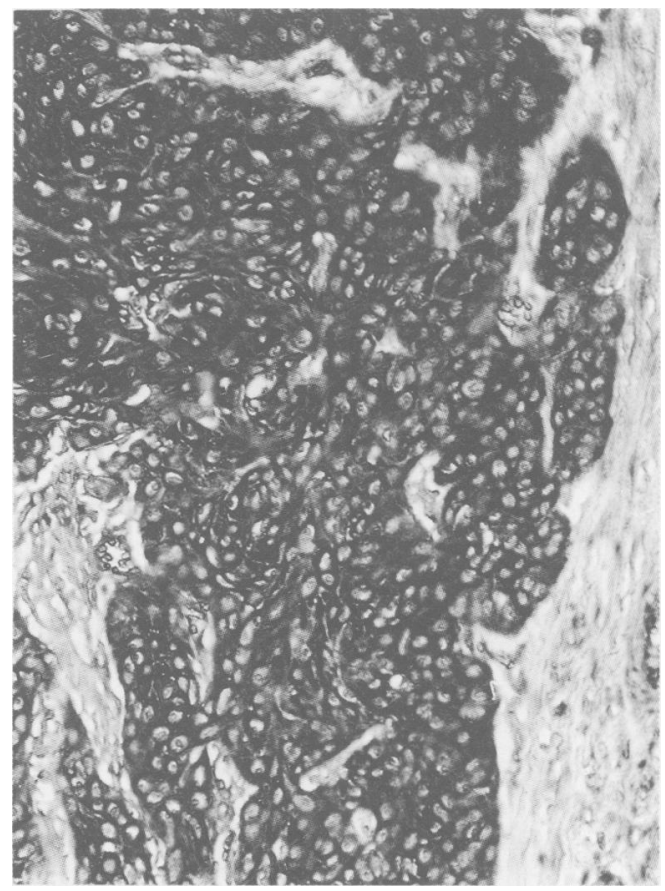

Figure 1: All the tumour cells of a moderately differentiated squamous carcinoma of oesophagus show CYPIA immunoreactivity (original magnification $\times 160$ ).

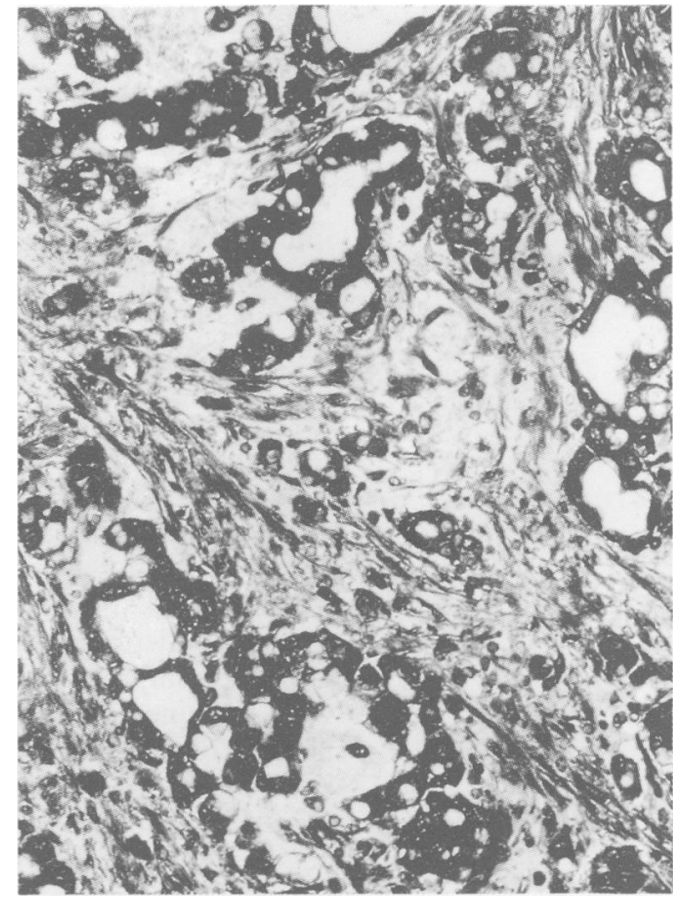

Figure 2: Immunoreactivity for epoxide hydrolase is identified within tumour cells of an adenocarcinoma of the oesophagus (original magnification $\times 160$ ).

was also seen. The immunoreactivity for each enzyme had a uniform distribution throughout each tumour. In addition, mast cells in normal and carcinoma samples consistently showed strong positive staining for CYP3A while glutathione S-transferase pi immunoreactivity was also identified in chronic inflammatory cells.

\section{Discussion}

We have investigated the expression of three specific sub-families of cytochrome $\mathbf{P 4 5 0}$

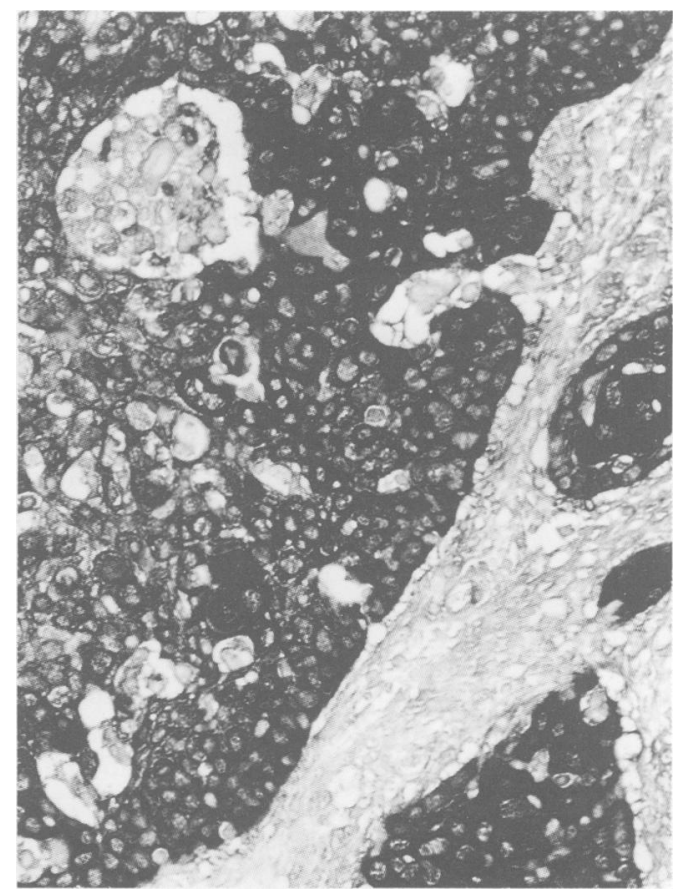

Figure 3: Expression of glutathione $S$-transferase alpha in an oesophageal squamous carcinoma. All the tumour cells show strong immunoreactivity (original magnification $\times 160$ ). 
(CYP1A, CYP2C, CYP3A) and the functionally associated enzymes epoxide hydrolase and glutathione S-transferase in oesophageal cancer and non-neoplastic oesophagus. The presence in the diet of carcinogens or pro-carcinogens, which can be metabolically activated is an important factor in the development of oesophageal cancer ${ }^{2}$ and these compounds are generally metabolised by the xenobiotic metabolising forms of cytochrome P450. The outcome of metabolism in terms of activation (toxicity) or deactivation (detoxification) will depend on the cellular localisation, comparative amount, and activity of the different xenobiotic metabolising enzymes present in a particular tissue. In nonneoplastic oesophagus there was only a low frequency of expression of the enzymes studied and in particular there was no expression of CYP3A. Samples of non-neoplastic oesophagus were obtained from the proximal resection margins of oesophagectomy specimens that contained tumour. Although these specimens displayed no histological abnormality they may not be functionally strictly normal, as they had been obtained from specimens that contained tumour. Ethically, however, it is not possible to obtain entirely normal oesophagus. A low level of P450 associated mono-oxygenase activity towards $N$ nitrosomethyl-n-amylamine has been identified in microsomes prepared from non-neoplastic human oesophageal mucosa although the particular form or forms of P450 contributing to this activity were not identified. ${ }^{22}$

Within the human alimentary tract CYP3A is present in a high concentration in the small intestine ${ }^{1823}$ but either absent or present at a low concentration from colon ${ }^{21}$ and it is suggested that a high concentration of CYP3A in the small intestine protects the small intestine from the development of cancer. ${ }^{24}$ Conversely, the absence of CYP3A from other sites in the alimentary tract may contribute to the frequent development of malignancy. The failure to detect immunoreactive CYP3A in nonneoplastic oesophagus may support this hypothesis.

There have been no extensive investigations of drug metabolising enzymes in oesophageal neoplasia. The only xenobiotic metabolising enzyme that has been studied in oesophageal malignancy is the pi class of glutathione Stransferase. ${ }^{24-27}$ Both glutathione S-transferase pi mRNA and protein are present in low amounts in non-neoplastic oesophagus but at an increased level in a high proportion of oesophageal squamous carcinomas.

The two different histological groups of oesophageal tumours, namely squamous carcinoma and adenocarcinoma, generally showed a similar pattern of expression of the different enzymes studied with the exception that the glutathione $\mathrm{S}$-transferases alpha and mu were expressed significantly less in adenocarcinoma than squamous carcinoma. The differential expression of these forms of glutathione S-transferase may provide an opportunity clinically for the improved selection of anti-cancer drugs based on knowledge of their metabolism by these forms of glutathione S-transferases.

Almost all the tumours displayed positive epoxide hydrolase immunoreactivity and we have previously identified epoxide hydrolase immunoreactivity in a variety of different malignant tumours including hepatoma, ${ }^{20}$ colon cancer, ${ }^{21}$ and breast cancer,${ }^{28}$ which suggests that epoxide hydrolase expression may be a common molecular event in malignancy.

In conclusion, we have found non-neoplastic oesophageal epithelium to be characterised by a low frequency of expression of different xenobiotic metabolising enzymes, with CYP2C and CYP3A being undetectable. In oesophageal cancer the phenotypic expression of the different enzymes was complex with the presence in at least $60 \%$ of all tumours of CYP1A and CYP3A, epoxide hydrolase and glutathione S-transferase pi. The frequent expression of the different xenobiotic metabolising enzymes in oesophageal cancer may contribute to the anti-cancer drug resistance that is characteristic of oesophageal cancer.

This work has been funded by grants from the Scottish Office Home and Health Department (K/MRS/50/C1699), Aberdeen Royal Hospital NHS Trust, and the Wellcome Foundation Ltd.

1 Saito T, Hikita M, Kohno M, Sato S-I, Takano H, Kobayashi $M$. Different sensitivities of human esophageal cancer cells to multiple anti-cancer agents and related mechanisms Cancer 1992; 70: 2402-9.

2 Cheng KK, Day NE, Duffy SW, Lam TH, Fok M, Wong J. Pickled vegetables in the aetiology of oesophageal cancer in Hong Kong Chinese. Lancet 1992; 339: 1314-8.

3 Guengerich FP. Metabolic activation of carcinogens. Pharmacol Ther 1992; 54: 17-61.

4 Guengerich FP. Oxidation of toxic and carcinogenic chemicals by human cytochrome P-450 enzymes. Chem Res Toxicol 1991; 4: 391-407.

5 Lu AYH, Miwa GT. Molecular properties and biological functions of microsomal epoxide hydrase. Annu Rev functions of microsomal epoxide

6 Board P, Coggan M, Johnston P, Ross V, Suzuki T, Webb G. Genetic heterogeneity of the human glutathione transferases: a complex of gene families. Pharmacol Ther 1990;48 357-69.

7 Guengerich FP. Roles of cytochrome P-450 enzymes in chemical carcinogenesis and cancer chemotherapy. Cancer Res 1988; 48: 2946-54.

8 Graham MA, Riley RJ, Kerr DJ. Drug metabolism in carcinogenesis and cancer chemotherapy. Pharmacol Ther 1991; 51: 275-89.

9 Kawajiri K, Fujii-Kuriyama Y. P450 and human cancer. F pn f Cancer Res 1991; 82: 1325-35.

10 Black SM, Wolf CR. The role of glutathione-dependent enzymes in drug resistance. Pharmacol Ther 1991; 51: 139 54.

11 Gonzalez FJ. Molecular genetics of the P-450 superfamily. Pharmacol Ther 1990; 45: 1-38.

12 Nelson DR, Kamataki T, Waxman DJ, et al. The P450 superfamily: update on new sequences, gene mapping accession numbers, early trivial names of enzymes and nomenclature. DNA Cell Biol 1993; 12: 1-51.

13 Powis G, Prough RA, eds. Metabolism and action of anticancer drugs. London: Taylor and Francis, 1987.

14 Le Blanc GA, Waxman DJ. Interaction of anticancer drugs with hepatic monooxygenase enzymes. Drug Metab Rev 1989; 20: 395-439.

15 Tsuchida S, Sato K. Glutathione transferases and cancer. Crit Rev Biochem Mol Biol 1992; 27: 337-84.

16 Murray GI, Foster CO, Barnes TS, et al. Cytochrome P450IA expression in adult and fetal human liver. Carcinogenesis 1992; 13: 165-9.

17 Barnes TS, Burke MD, Melvin WT. Differences in adult and foetal human cytochrome P-450 forms recognized by monoclonal antibodies with specificity for the P450III family. Biochem F 1989; 260: 635-40.

18 Murray GI, Barnes TS, Sewell HF, Ewen SWB, Melvin WT Burke MD. The immunocytochemical localisation and distribution of cytochrome P-450 in normal human hepatic and extrahepatic tissues with a monoclonal antibody to human cytochrome P-450. Br F Clin Pharmacol 1988; 25 . 465-75

19 Weaver RJ, Dickins M, Burke MD. Cytochrome P450 2C9 is responsible for hydroxylation of the naphthoquinone antimalarial drug $58 \mathrm{C} 80$ in human liver. Biochem Pharmacol 1993; 46: 1183-97.

20 Murray GI, Paterson PJ, Weaver RJ, Ewen SWB, Melvin WT, Burke MD. The expression of cytochrome P450, WT, Burke MD. The expression of cytochrome P450,
epoxide hydrolase and glutathione S-transferase in hepatoepoxide hydrolase and glutathione S-transf

21 McKay JA, Murray GI, Weaver RJ, Ewen SWB, Melvin WT, Burke MD. Xenobiotic enzyme expression in colonic neoplasia. Gut 1993; 34: 1234-39. 
22 Huang Q, Stoner G, Resau J, Nickols J, Mirvish SS. Metabolism of $\mathrm{N}$-nitrosomethyl-n-amylamine by microsomes from human and rat esophagus. Cancer Res 1990; 52: 3547from
K1.

23 Kolars JC, Schmiedlin-Ren P, Schuetz JD, Fang C, Watkins PB. Id (CYP3A4) in human small bowel enterocytes. $\mathcal{F}$ Clin Invest 1992; 90: 1871-8.

24 Kaminsky LS, Fasco MJ. Small intestinal cytochromes P450. Crit Rev Toxicol 1992; 21: 407-22.

25 Ishioka C, Kanamaru R, Shibata $\mathrm{H}$, et al. Expression of glutathione-S-transferase-pi messenger RNA in human oesophageal cancers. Cancer 1991; 67: 2560-4.

26 Tsuchida S, Sekine Y, Shineha R, Nishihira T, Sato K Elevation of the placental glutathione S-transferase form Elevation of the placental glutathione S-transferase form
(GST- $\pi$ ) in tumor tissues and the levels in sera of patients with cancer. Cancer Res 1989; 49: 5225-9. 27 Terrier P, Townsend AJ, Coindre JM, Triche TJ, Cowan KH An immunohistochemical study of pi class glutathione $S$ transferase expression in normal human tissue. Am F Pathol 1990; 137: 845-53.

28 Murray GI, Weaver RJ, Paterson PJ, Ewen SWB, Melvin WT, Burke MD. Expression of xenobiotic metabolising enzymes in breast cancer. F Pathol 1993; 169: 347-53. 